\title{
Cardiac lesions in fatal cases of recent myocardial ischaemia from a coronary care unit
}

\author{
D. C. Bouch and G. L. Montgomery \\ From the Department of Pathology, University of Edinburgh
}

In 100 consecutive deaths from a coronary care unit, the coronary arteries were examined microscopically in longitudinal sections (serial and semi-serial) so that the entire extramural part of each artery was scrutinized. Occluded coronary arteries were found in 88 cases, the occlusions being due to thrombi in 17 , to the contents of soft atheromatous plaques in 22, and to a mixture of soft plaque content and thrombus in 49; thus in $7 I$ cases the coronary occlusions are due basically to the rupture of soft plaques. After deep-freezing, the entire myocardium of each heart was examined naked eye in serial slices (using Nitro-BT) and selected areas microscopically. The findings allowed tentative groupings into single episode, double episode, and progressive lesions according to age structure. Correlation of the coronary and myocardial findings has been attempted.

The establishment of a coronary care unit in the Royal Infirmary of Edinburgh provided an opportunity to make a detailed study of the hearts of fatal cases with especial reference to the condition of the coronary arteries in relation to the myocardial lesions. The policy of the unit is to admit ' $(I)$ any patient under 70 years of age who is suspected of having sustained a myocardial infarction within the preceding 48 hours ("routine admission"); and (2) any patient of any age who has a dangerous arrhythmia' (Lawrie et al., 1967).

\section{Materials and methods}

The cases which comprise this series had been admitted to the coronary care unit between I January I968 and 30 June 1969. During that time I ro9 patients were admitted and 132 died: of those, III ( $84 \%$ ) were examined post mortem. After a preliminary survey, I I cases were excluded from the series either because of complications of various kinds (e.g. valvular disease) or because there was no clinical or pathological evidence to suggest recent myocardial ischaemia. With those exceptions, the remaining cases were consecutive and numbered 100. The decision to close the series was partly a matter of convenience and partly because we intend to look at other cardiac problems by different means.

The majority of the necropsies took place within 24 hours of death. All bodies were placed in a refrigerated mortuary within an hour or so of death and maintained at $-4^{\circ} \mathrm{C}$. until dissection. Necropsies were performed by the duty patholo-

Received 25 February 1970. gists, and hearts from all the coronary care unit cases were set aside for examination by one or other of the authors. After weighing the organ, the coronary arteries were dissected from the heart, the right, left anterior, and left circumflex vessels being traced from their orifices as far as possible on the external cardiac surface. The unopened arteries were fixed separately in neutral Io per cent formal saline for 18 to 24 hours before trimming by removal of adherent fat. With a sharp scalpel, each vessel was cut into pieces about $2 \mathrm{~cm}$. long, beginning peripherally and as far as possible placing the cuts so as to avoid an occlusion. Calcified segments were also left uncut until decalcified.

The arterial segments were embedded in paraffin so that longitudinal sections would expose the whole length of the lumen. Complete serial sections at $5 \mu$ were made from selected blocks where occlusion was seen or believed to have occurred; these amounted to half the cases. In other cases not cut serially, semi-serial sections were taken off at different levels until the whole lumen of the vessel was available for examination. Routine stains were employed and all the sections were scrutinized by the authors separately.

After removal of the coronary arteries, the hearts were placed in a deep-freeze cabinet at $-20^{\circ} \mathrm{C}$. suspended from glass rods to preserve the shape of the heart. When convenient, the hearts were thawed to a suitable consistency at room temperature, and sliced on a Berkel automatic slicer. Transverse sections from apex to base of the ventricles were taken at approximately $5 \mathrm{~mm}$. thickness, the valves and atria being examined separately. All the sections were scrutinized with care, while every fourth section after washing in running, warm water was incubated in an aqueous solution of Nitro Blue Tetrazolium 
(Nitro-BT) at $37^{\circ} \mathrm{C}$. for 30 minutes (Nachlas and Shnitka, 1963). Experience in this department has shown that ischaemia in cardiac muscle of as short a duration as two hours can be demonstrated by this method. The gross localization, extent, and nature of old and recent coronary and myocardial lesions were charted on diagrammatic proformas.

Tissue was selected from the transverse sections for histological examination. These included in every case two blocks from the area of myocardium supplied by each coronary artery, irrespective of the pattern of its disease, one block being taken from near to the apex and the other from near to the base. A minimum of six myocardial blocks was therefore taken for each case. If, as indicated after the incubation of the heart slices in Nitro-BT, the routine blocks were not sufficiently representative, then further blocks were taken from those areas indicated. Histological sections prepared after paraffin embedding were stained with haematoxylin and eosin.

\section{Results}

It was found convenient to classify the findings according to the main lesions in the coronary arteries, and in this way the series fell into four groups - A, B, C, and D (Table I).

TABLE I Features of coronary lesions

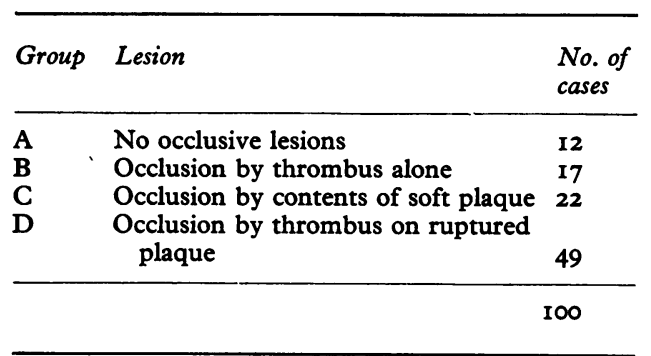

In Table 2 the groups have been arranged to show the numbers and ages of the cases together with the heart weights for each sex.

All the hearts in the series had extensive recent ischaemic damage, and in addition the majority showed evidence of previous ischae$\mathrm{mia}$ in the forms of diffuse fibrosis and the scars of healed infarcts. The distinction between these terms is arbitrary. In our connotation, diffuse fibrosis refers to numerous small ischaemic scars sometimes seen naked eye and invariably demonstrable microscopically: healed infarcts have much larger and characteristic scars which are unequivocal. The incidence of these lesions in relation to associated organized occlusions in the coronary arteries is summarized in Table 3.

Table 4 gives the distribution and incidence of occlusions by arteries for each group.
TABLE 2 Numbers, age, and heart weights in relation to sex for each group

\begin{tabular}{|c|c|c|c|c|}
\hline & & No. & $\begin{array}{l}\text { Mean age } \\
(y r .)\end{array}$ & $\begin{array}{l}\text { Mean heart } \\
\text { weight (g.) }\end{array}$ \\
\hline \multirow[t]{2}{*}{$\underset{\text { A }}{\text { Group }}$} & Men & 5 & $\begin{array}{l}55 \cdot 2 \\
(45-64)\end{array}$ & $\begin{array}{l}540 \\
(360-750)\end{array}$ \\
\hline & Women & 7 & $\begin{array}{l}56 \cdot 7 \\
(44-66)\end{array}$ & $\begin{array}{l}370 \\
(270-550)\end{array}$ \\
\hline \multirow[t]{2}{*}{$\begin{array}{c}\text { Group } \\
\text { B }\end{array}$} & Men & II & $\begin{array}{l}56 \cdot 3 \\
(46-62)\end{array}$ & $\begin{array}{l}470 \\
(360-770)\end{array}$ \\
\hline & Women & 6 & $\begin{array}{l}65 \cdot 1 \\
(63-77)\end{array}$ & $\begin{array}{l}430 \\
(280-540)\end{array}$ \\
\hline \multirow[t]{2}{*}{ Group } & Men & 15 & $\begin{array}{l}62 \cdot 5 \\
(46-82)\end{array}$ & $\begin{array}{l}480 \\
(360-600)\end{array}$ \\
\hline & Women & 7 & $\begin{array}{l}63.7 \\
(55-77)\end{array}$ & $\begin{array}{l}410 \\
(300-550)\end{array}$ \\
\hline $\begin{array}{c}\text { Group } \\
\text { D }\end{array}$ & $\begin{array}{l}\text { Men } \\
\text { Women }\end{array}$ & $\begin{array}{l}30 \\
19\end{array}$ & $\begin{array}{l}62 \cdot 8 \\
(43-88) \\
60 \cdot 8 \\
(53-70)\end{array}$ & $\begin{array}{l}490 \\
(250-650) \\
380 \\
(290-510)\end{array}$ \\
\hline
\end{tabular}

The figures within the brackets represent the range in our cases.

TABLE 3 Distribution of diffuse fibrosis, healed myocardial infarcts (scars), and previous coronary occlusions, by groups

\begin{tabular}{|c|c|c|c|}
\hline Group & $\begin{array}{l}\text { No. of hearts } \\
\text { showing } \\
\text { diffuse } \\
\text { fibrosis }\end{array}$ & $\begin{array}{l}\text { No. of hearts } \\
\text { showing } \\
\text { healed } \\
\text { infarcts }\end{array}$ & $\begin{array}{l}\text { No. of hearts } \\
\text { with healed } \\
\text { infarcts and old } \\
\text { coronary } \\
\text { occlusion }\end{array}$ \\
\hline A & $\begin{array}{l}\text { II } \\
(91 \cdot 6 \%)\end{array}$ & $\stackrel{9}{(75 \cdot 0 \%)}$ & $\stackrel{2}{(22 \cdot 1 \%)}$ \\
\hline B & $\begin{array}{l}13 \\
(76 \cdot 0 \%)\end{array}$ & $\begin{array}{l}\text { I0 } \\
(58.8 \%)\end{array}$ & $\begin{array}{c}4 \\
(40 \cdot 0 \%)\end{array}$ \\
\hline C & $\begin{array}{l}16 \\
(72 \cdot 6 \%)\end{array}$ & $\begin{array}{c}8 \\
(36 \cdot 4 \%)\end{array}$ & $\begin{array}{l}3 \\
(37.5 \%)\end{array}$ \\
\hline D & $\begin{array}{l}40 \\
(81 \cdot 6 \%)\end{array}$ & $\begin{array}{l}26 \\
(53.0 \%)\end{array}$ & $\begin{array}{l}\text { II } \\
(42 \cdot 3 \%)\end{array}$ \\
\hline
\end{tabular}

TABLE 4 Distribution and incidence of occlusions by arteries for each group

\begin{tabular}{llllll}
\hline Group & $\begin{array}{l}\text { Total } \\
\text { cases }\end{array}$ & $\begin{array}{l}\text { No. of occluded coronary } \\
\text { arteries }\end{array}$ & $\begin{array}{l}\text { Total } \\
\text { no. of } \\
\text { occluded } \\
\text { vessels }\end{array}$ \\
\cline { 3 - 6 } & & $\begin{array}{l}\text { Lt. } \\
\text { anterior } \\
\text { desc. }\end{array}$ & $\begin{array}{l}\text { Lt. } \\
\text { circumflex }\end{array}$ & Right & \\
\hline A & 12 & - & - & - & - \\
B & 17 & 13 & I & 3 & 17 \\
C & 22 & 10 & 6 & 9 & 25 \\
D & 49 & 19 & 5 & 28 & 52 \\
\hline
\end{tabular}

Group A: no occlusive lesion (12 cases, 5 men, 7 women) In this group, though no occlusive lesion was identified in any of the coronary arteries, those vessels were severely stenosed by atherosclerosis, and sometimes 
only of pinpoint size. The atheroma was largely of the hard type, occasional soft plaques being deeply situated and covered by relatively thick layers of hyaline material. The small scars of diffuse fibrosis (I I hearts) were most numerous in the ventricular subendocardium. Healed myocardial infarcts were present in 9 hearts with associated organized arterial occlusions in 2 of them.

The recent myocardial damage consisted of a terminal component never exceeding 72 hours in age. In 3 hearts this was obviously the end result of a progressive lesion which showed a spectrum of histological changes from necrosis to early organization, with large numbers of capillary blood vessels and macrophages. In every case the recent ischaemic damage was concentric, involving the inner part of the left ventricular myocardium, and in 9 of the hearts, the infarct extended also into the distribution area of one of the coronary arteries.

There were 2 ventricular ruptures into the pericardium, both in lesions approximately 48 hours old.

Group B: occlusion by thrombus alone (I 7 cases, II men, 6 women) One coronary artery in each heart was occluded by thrombus alone; 13 occlusions occurred in the left anterior descending, 3 in the right coronary, and $I$ in the left circumflex artery. All the vessels had severe, irregular stenosis, largely due to atheroma of the hard type. The few soft plaques were usually separated from the lumen by a thick layer of hyaline material. In every instance the occlusive thrombi had formed where the lumen was severely stenosed and were not related to soft plaques. Former ischaemic damage with diffuse fibrosis was noted in the left ventricles of 13 hearts. Healed infarcts were present in Io hearts with associated organized arterial occlusions in 4 of them.

The recent ischaemic damage was essentially in the distribution areas of the recently occluded arteries, consisting of a terminal component not exceeding 72 hours in age; in 9 it had been the final event of a progressive organizing process, in 3 it was superimposed on a collagenous scar. It was noted further that in the majority of the 9 cases with organization, the occluding thrombi were composed of older and recent parts.

There were 2 ventricular ruptures which occurred in lesions 3 and 5 days old, respectively.

Group C: occlusion by contents of soft plaque (22 cases, 15 men, 7 women) In all those cases, at least one artery was occluded by soft atheromatous debris. The distribution of the occlusion between the 3 main coronary arteries is shown in Table 4. In all, 25 vessels were occluded, with single-vessel occlusion in 19, and double-vessel occlusion in the remaining 3 hearts. The atheroma in this group was predominantly of the soft type whether or not occlusion had occurred.

Stenosis was irregular and of moderate severity. The occlusions were due to soft atheromatous debris often containing cholesterol crystals and usually mixed with blood, blocking the artery at and for a short distance beyond an eroded soft plaque. The length of the erosions varied from about 100 $\mu$ to $2 \mathrm{~mm}$.

In II of the hearts the recent myocardial damage was less than 24 hours old and included the 3 hearts having 2 occluded coronary arteries. In the majority of these II hearts the recent myocardial damage was identified only by Nitro-BT. There was a relatively high incidence of progressive lesions ( 8 hearts) upon which terminal damage had been superimposed. Only I heart showed recent myocardial damage as an extension to a healed infarct.

There was I ventricular rupture occurring in a lesion estimated at about 5 days old.

Group D: occlusion by thrombus formed in relation to ruptured soft plaque (49 cases, $30 \mathrm{men}$, 19 women) This largest group is characterized by the occlusion of at least one coronary artery by recent thrombus which had formed on a ruptured soft plaque. A single artery was occluded in 46 hearts, 2 arteries in each of the 3 other hearts. Numerous large soft atheromatous plaques capped by very thin layers of hyaline material were features of occluded vessels.

Diffuse fibrosis occurred in 40 hearts, 26 had healed infarcts, with organized coronary arterial occlusions in $\mathrm{I}$.

A feature of this group was extensive terminal ischaemic myocardial damage which had developed during the last 24 hours of life. In 37 hearts this terminal damage was superimposed upon an earlier and smaller infarct, in 7 it was coupled with progressive organization, and in 5 the recent ischaemia was associated with a healed infarct.

There were 3 ventricular ruptures, 2 in lesions estimated at 3 days old, and $I$ in a lesion approximately 5 days old.

\section{Discussion}

The results are mainly concerned with the findings in the coronary arteries and in the left ventricular myocardium. Changes in the 
atria and right ventricle have not been included and we have not attempted direct clinical correlation.

Coronary artery occlusion It is well recognized that thrombotic occlusion is not always demonstrable in myocardial infarcts associated with atherosclerosis of the coronary arteries. Montgomery (1959) reported that of I08 infarcted hearts, no occlusion could be found in the extramural coronary arteries in $45(42 \%)$ of them, though the vessels were gravely stenosed. Similar absence of occlusion, though in varying percentages and instances, had been reported previously by Davenport (1928), Gross and Sternberg (1939), and Master et al. (194I, 1944), and more recently by Crawford, Dexter, and Teare (196I) and by Kagan et al. (1968). In the series reported by Crawford and his colleagues, of 75 hearts examined from cases of sudden death, $34(45 \%)$ did not show recent coronary occlusions. The paper of Kagan et al. comprised the accumulated evidence from three communities in Malmo, Prague, and Yalta, over a 4-year period from January 1963 to December 1966 . There were 176 cases of sudden death due to coronary heart disease, and of those, 25 per cent of the hearts did not disclose any thrombotic or other occlusion of the coronary arteries.

Most of the earlier workers examined the arteries by transverse free-hand sections, 2-3 $\mathrm{mm}$. apart, supplemented in some instances by microscopical sections of suspicious or occluded portions. Crawford et al. employed an injection technique to localize the stenosed segments radiographically, which thereafter were sectioned transversely and examined microscopically. Kagan et al. also used transverse sections cut free-hand, about 2 $\mathrm{mm}$. apart. In the series reported by Montgomery, the hearts were sliced mechanically after freezing but differed from our present series in having the coronary arteries in situ. Thus, though the method had the initial advantage of providing a rapid means of examining whole hearts, it was not ideal because the extramural coronaries were often cut in oblique or tangential sections. Moreover, to obtain satisfactory slices, the frozen hearts had to be thawed to a critical softness which undoubtedly prevented the satisfactory cutting of coronary arteries in some instances; calcified arterial walls had a similar effect. In retrospect, too, deep-freezing of the whole heart with intact coronaries may have loosened recent thrombi and probably accounted for the large number of non-occlusive thrombi. Accordingly, when the opportunity arose to examine the hearts of the coronary care unit cases, we decided to avoid those potential artefacts by removing the coronary arteries from the hearts before they were frozen.

In this series, the proportion of coronary occlusions $(88 \%$ of the hearts examined) is relatively high and certainly higher than in the earlier series reported from this department (Branwood and Montgomery, 1956; Montgomery, 1959). To some extent the variation is undoubtedly a matter of technique. The practice we adopted of cutting the coronary arteries in 3,4 , and 5 longitudinal blocks, each about $2 \mathrm{~cm}$. long, has given information not obtainable from transverse sections. Further, a high proportion of the occluded segments and those suspected of occlusion were cut in serial sections and every section made available for examination. Arteries not cut serially were cut at numerous levels as required until the complete lumen of the segment was disclosed. Accordingly we are satisfied that every vessel has been examined thoroughly and no occlusion omitted.

Though technique was undoubtedly a major factor in securing so high an incidence of occlusion, it may be that the source of the material is also significant. For instance with the exception of a few patients who died before treatment could be effective, all the hearts came from patients who had received intensive care and treatment. It is not inconceivable that some patients without occlusion survive under those circumstances whereas they formed a substantial proportion of the deaths in former series. Thrombosis occurring as a late event in the illness could be accounted for in that way. Obviously any explanation will remain speculative but it may be recorded that there was a notable absence of old occlusions and signs of former haemorrhage in the coronary arteries of this entire series of cases.

Nature of coronary occlusions Since Leary (1935) described the lesion which he named an atheromatous abscess, most workers in this field have appreciated that the soft plaques are the most dangerous by virtue of their tendency to rupture and induce thrombosis. In 71 of the 100 cases in our series, the infarct was directly attributable to rupture of a soft plaque: in 50 of the 71 , thrombus had formed on the ulcerated plaque, and in 21 cases, the occlusion of the coronary artery was due to the discharged atheromatous contents of the soft plaque without demonstrable thrombus. It is our experience that longitudinal sections are better than transverse to demonstrate those lesions, and that serial sections add greatly to the accuracy of the obser- 
vations. In this way it is possible to show, for instance, that rupture of a soft plaque may be limited to a very short length of a vessel, measurable usually in microns and seldom as long as $2 \mathrm{~mm}$. The discharge of the contents into the lumen may produce a sudden or complete block (Fig. I) or may give rise to multiple emboli of atheromatous material into the finer intramural branches of the coronary arteries. On the other hand, there is abundant proof that thrombosis when it occurs in those circumstances is associated with a mixture of plaque content and thrombus (Fig. 2). The occlusive material contains macrophages from the plaque; cholesterol clefts mark the inclusion of crystals which had formed in the plaque; and in longitudinal sections it is possible to see how, from such a focal lesion, thrombus of varying age may propagate along the vessel, sometimes in both directions. Thus, there appears to be a distinction between the discharge of content from a ruptured plaque and the process of thrombosis in relation to an ulcerated plaque. A ruptured plaque has lost some of its content into the lumen and thereby may no longer be swollen and under tension: where the surface only is absent, fibrin and red blood corpuscles may mingle with its superficial contents. Friedman and Van den Bovenkamp (1966), using transverse semiserial sections, found that in 39 of 40 cases, the coronary thrombosis was due to rupture of a soft plaque and to the mixture of its contents with the circulating blood. They demonstrated communications (or fractures) in the portion of the arterial wall which separates the lumen from the necrotic contents of the soft plaques, and emphasized the importance of the direction taken by the fragmented ends of the ruptured wall, interpreting the findings to indicate a flow of atheromatous gruel or blood into the lumen and not in the reverse direction: thus they inferred that direct communication between the lumen and the abscess preceded the thrombosis in almost every case, a view with which we are in agreement so far as soft plaques are concerned (Fig. 3).

Possibly the most arresting feature is that the soft plaques are often protected from ulceration and rupture by extremely slender barriers (Fig. 4). Frequently only a few hyaline strands provide the barrier 20-30 $\mu$ thick which separates the contents of the plaque from the circulating blood. Endothelial cells are rarely seen. The fibrils lie parallel with the lumen. They take the aniline blue of the picro-Mallory stain and they are undoubtedly derivatives of fibrin: indeed strands of recent fibrin can sometimes be seen on their surface.

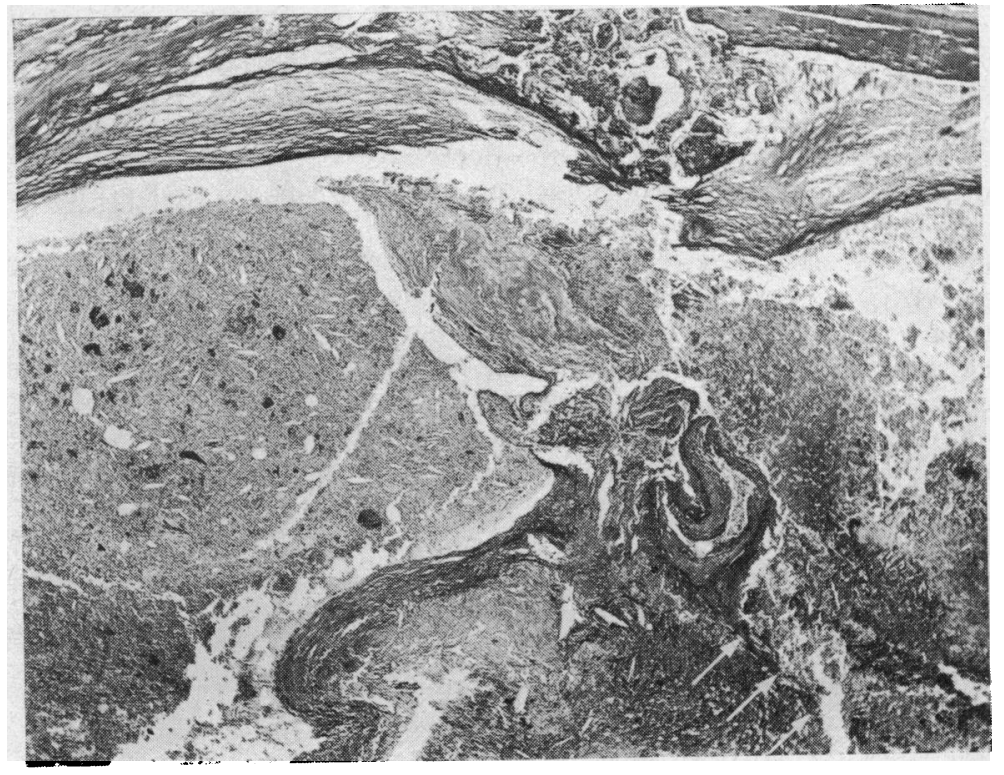

FIG. I Coronary artery occluded by the contents of a soft plaque. The arrows indicate part of the ulcerated surface of the plaque. (Haematoxylin and eosin $\times 25$.)

FIG. 2 Coronary artery occluded by contents of soft plaque and thrombus. The blood has infiltrated into the plaque. (Haematoxylin and eosin $\times 25$.)

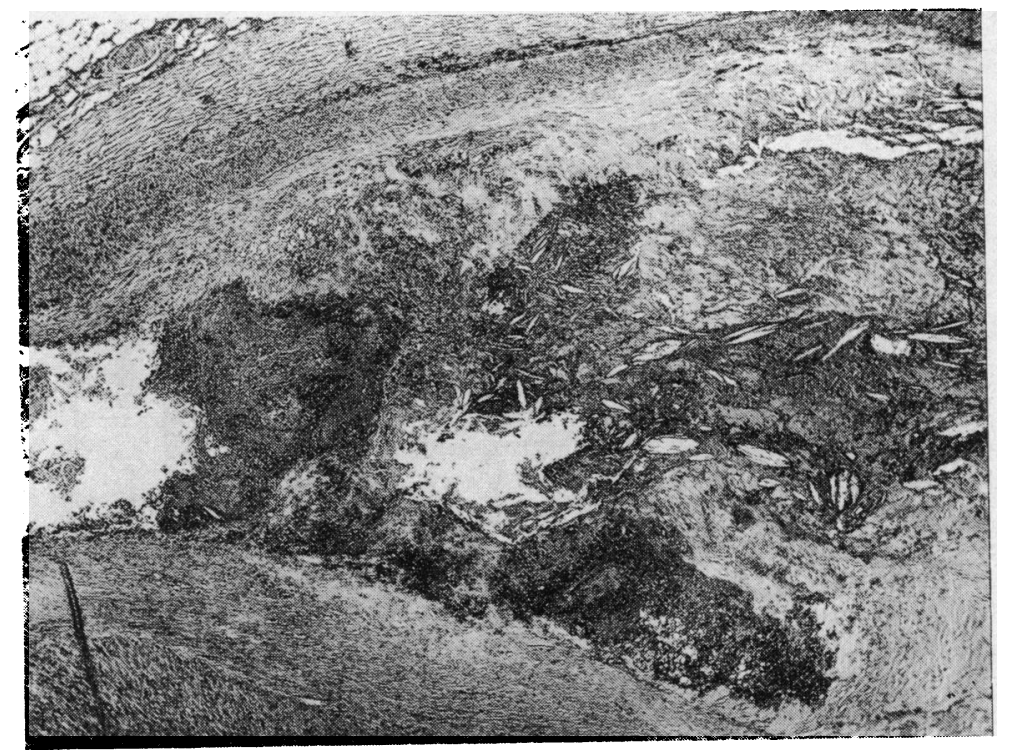


Presumably fibrils are removed and added to from time to time. Loosening of the superficial hyaline fibrils would be sufficient for ulceration to take place, and it is not difficult to find examples where oedematous loosening of the fibrils has occurred. Sometimes spaces between the fibrils are occupied by lipophages, and many sections give the impression that the entry of blood from the lumen is a common event. Time and again sections show erythrocytes mingled with the hyaline strands, continuous with the blood in the lumen and with thrombus if it is present. Occasionally there is a type of microdissection with a channel of blood lying beneath a shallow fibrillar hyaline layer, obviously a preliminary to ulceration. It is clear that this blood enters from the lumen and is under pressure: we have not seen superficial capillaries in the plaques, and we cannot say whether capillary rupture as described by Paterson (1936) plays any part; certainly we have no evidence in favour of that view. Probably ulceration occurs in several ways and may be aided by active movement of the artery. Gore (1963) has pointed out that rupture usually occurs at the periphery of a plaque where it is liable to be loosened from the underlying wall.

In addition to the barrier of fibrillary hyaline which separates the soft contents of plaques from the blood in the lumen, one or more similar septa are often seen in the substance of soft plaques. They lie roughly parallel with the surface and divide the plaque into strata. Each of those septa must represent episodes of fibrin formation (mural thrombi) in or upon which lipid is subsequently deposited (Fig. 5).

Constantinides (I966) published an interesting group of 20 consecutive cases of coronary occlusions in which the occluded arterial segments were cut serially in transverse sections. He showed that in every instance the thrombus was anchored at a fissure in a plaque which he believed to be causally related to thrombus formation. The fissures were longitudinal in direction and in the line of the lumen: they varied from slits $100 \mu$ wide to larger cracks $1000 \mu$ wide.

In $7 \mathrm{I}$ of the 100 cases in our series, similar breaches of continuity occurred and invariably on the surface of soft plaques, and we regard those as examples of plaque ulceration and rupture.

In a few instances where thrombus had formed on the hard plaques of stenotic arteries, we noted minute indentations in longitudinal sections (Fig. 6) filled with platelet/fibrin plugs and presumably causally related with the thrombosis. On the other

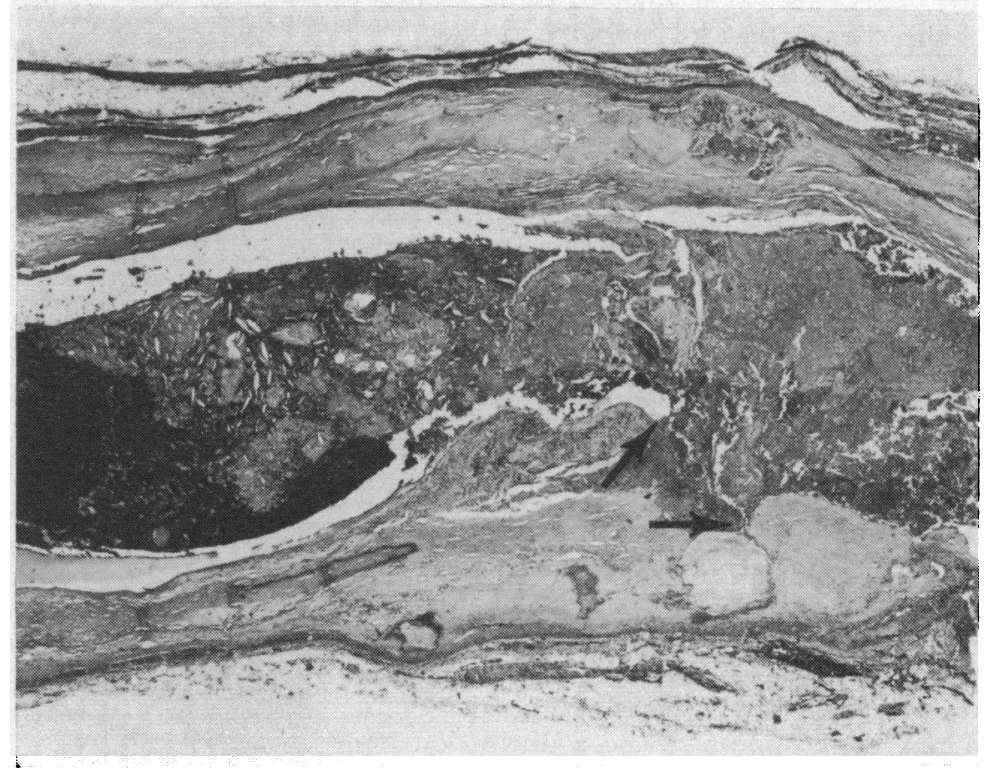

FIG. 3 Coronary artery in which a soft plaque has ruptured (arrows) and the vessel is occluded by a mixture of plaque contents and thrombus which extends to meet dark-staining blood clot. (Haematoxylin and eosin. $\times$ I I.)

FIG. 4 The structure of a soft plaque is illustrated. Note the extremely thin hyaline covering next the lumen at the top of the photograph. (Haematoxylin and eosin. $\times 50$.)

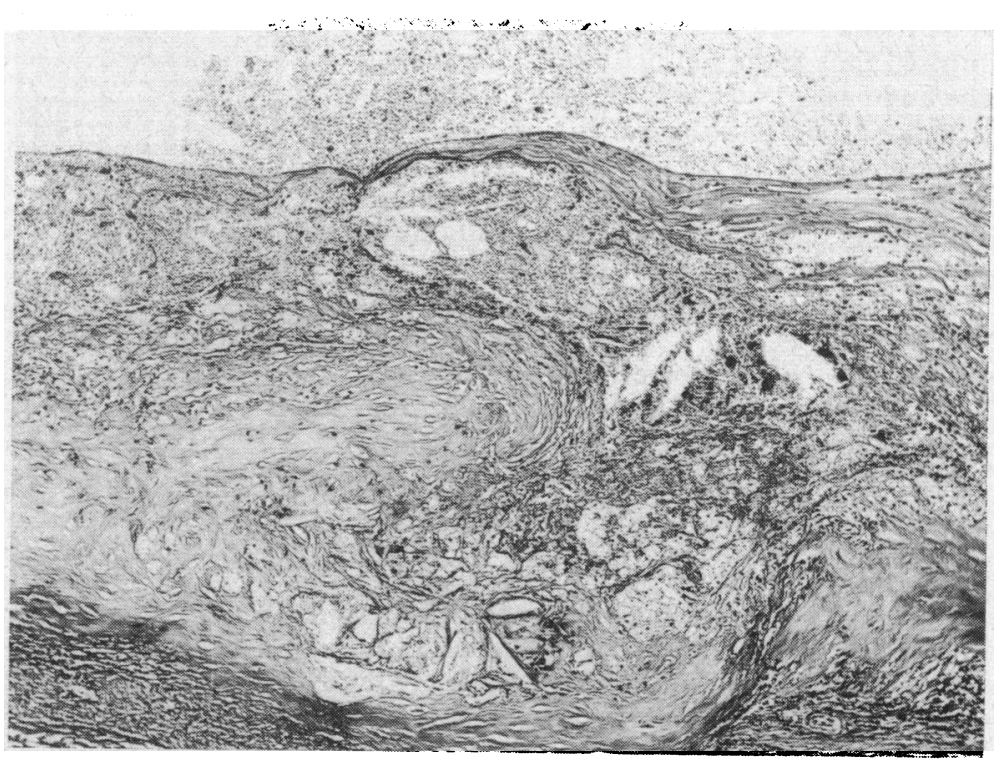


hand, we saw many similar indentations which contained no thrombotic elements. This is a point to which we paid considerable attention, and so far as our series is concerned surface irregularities in hard plaques contributed little to the formation of occlusive thrombi. Our impression is that in coronary arteries with hard plaques, stenosis is the most important thrombotic factor.

As in previous series examined from this department, the incidence of hard and soft plaques seemed haphazard. Sometimes all three coronary arteries in a heart were heavily involved in soft atheroma, and as the sections were followed lengthwise, several potential points of rupture could be identified. In other hearts two, and sometimes only one, of the three vessels were involved in soft atheroma, the others in hard plaques. Constantinides (1965) showed by his experiments in rabbits on lipid diets that injury to the arterial wall was a prerequisite of lipid deposition.

Myocardium Slicing hearts after deepfreezing proved an effective means of identifying myocardial lesions naked eye and microscopically. Collagenous scars and recent infarcts were easily seen and the microscopical structure was sufficiently well preserved to allow an estimate of the age of the lesions. For this purpose we used the time scale introduced by Mallory, White, and Salcedo-Salgar (1939) and essentially confirmed by LodgePatch (1951), which was adequate for the assessment of the relative duration of ischaemic damage.

Nitro-BT was used routinely in the series to identify the recent lesions. It was particularly useful in identifying those lesions which did not show unequivocal signs of ischaemia (less than 24 hours' duration), especially when they were terminal extensions to established lesions. The significance of these appearances is open to question: there is no certainty that at least some of the very early ischaemic tissue, identifiable only with Nitro-BT, may not have been viable, and for this reason we have avoided the name 'infarct' for these areas. Nevertheless it is an advantage of Nitro-BT that blocks for microscopy can be taken from tissue which otherwise might not have been examined, and our experience in this series is that such tissue showed the irregular staining of the sarcoplasm and the fragmentation of the muscle fibres usually accepted as criteria of early ischaemic damage. Moreover careful examination of those areas not infrequently disclosed early neutrophil infiltrate.

The relation of the infarcts to the coronary lesions deserves comment. Acute ischaemic

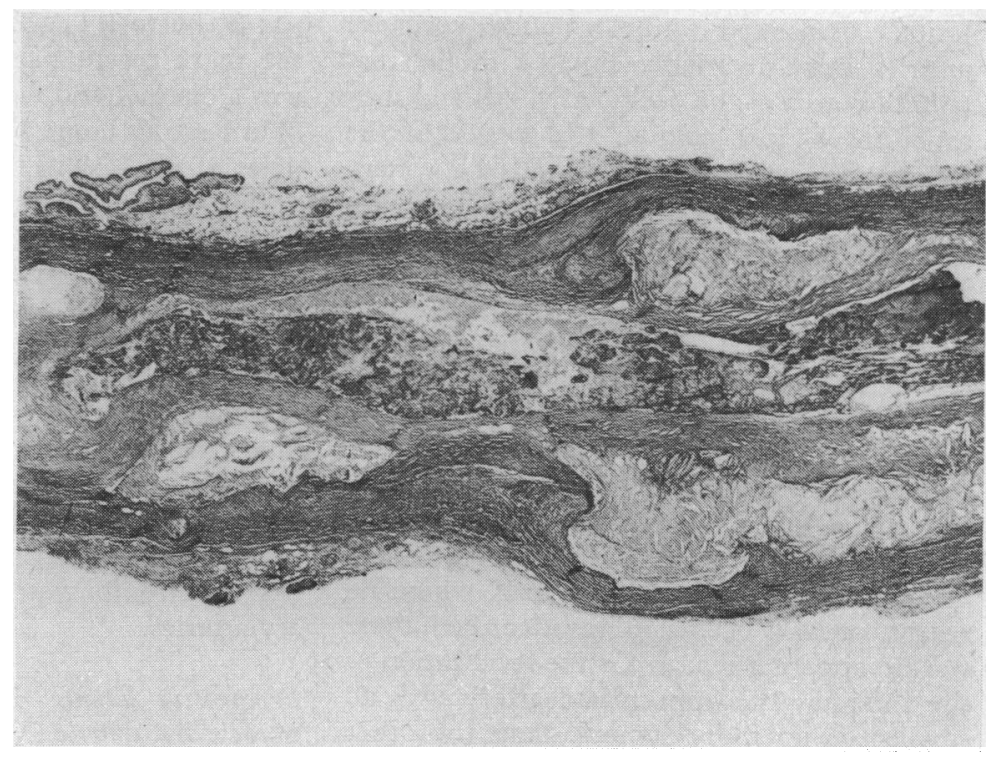

FIG. 5 Stenosed coronary artery occluded by thrombus of varying age. Note the extensive soft plaques with substantial hyaline caps. (Haematoxylin and eosin. $\times$ IO.)

FIG. 6 Stenosed coronary artery occluded by thrombus. Two platelet/fibrin plugs can be seen in indentations on the lower surface, and one small plug on the upper surface of the thrombus. (Haematoxylin and eosin. $\times 30$.)

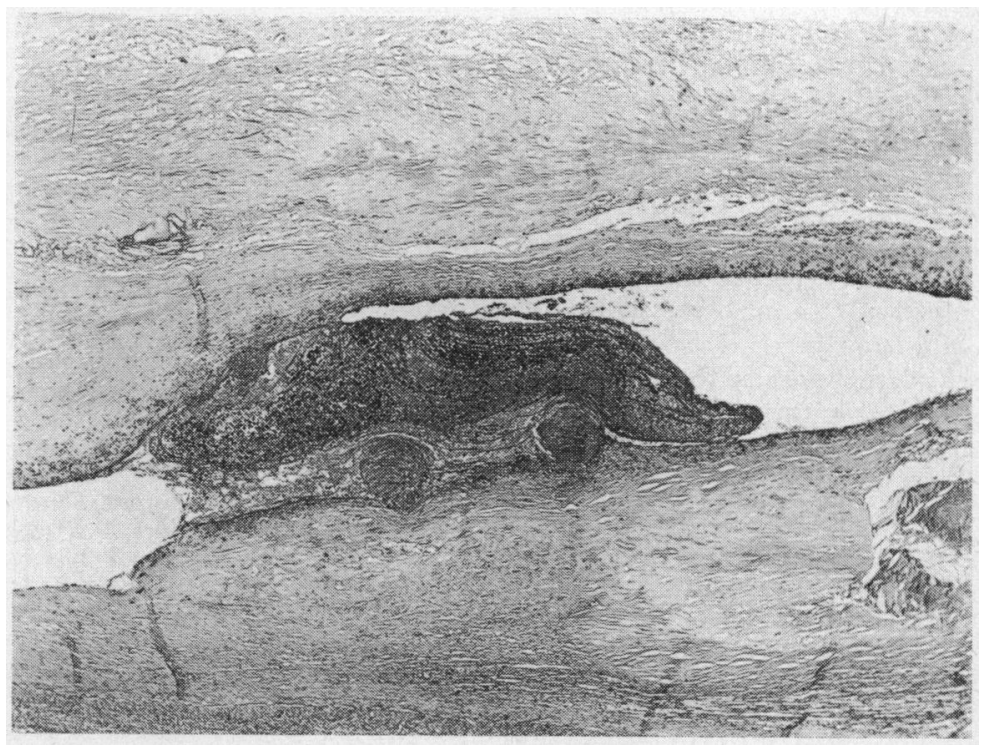


lesions associated with occluded coronary arteries were invariably situated in the distribution area of the occluded vessel and they represent 88 per cent of the total. On the other hand relatively few organized coronary artery lesions were disclosed in association with old healed infarcts. Substantial collagenous scars were found in 53 (i.e. more than half) hearts in the series, but only 20 of them had evidence of a former coronary artery occlusion. Though it is realized that this series is too small to allow conclusions, those figures add support to the suggestion already made in this paper that patients with acute myocardial ischaemia without coronary artery occlusions may have a greater chance of survival. It is to be noted also that in the cases in Group A where no recent coronary occlusion was identified, there was no apparent reason for the localization of the infarcts; the appropriate artery was no smaller or no more stenotic than the other coronary arteries of the heart.

Nature of recent myocardial lesions Study of the age structure of the recent myocardial damage allows a grouping into 3 patterns which we have named single episode lesions, double episode lesions, and progressive lesions.

Single episode lesions In each of 36 hearts the recent myocardial lesion represented a single episode of ischaemia. In 32 of them these lesions were less than 3 days old, and included 17 where the duration of the recent damage did not exceed 24 hours. By allotting these 17 cases to the categorized coronary groups, 3 occurred in group A, I in group B, I I in group $C$, and 2 in group D. Thus of the 22 cases in group C, I I did not survive the acute onset of ischaemia for more than 24 hours, and this is the group where the coronary arteries were blocked by the contents of ruptured soft plaques without thrombosis. Obviously this type of case will need to be studied in much greater numbers and detail, but from this evidence it appears that the sudden blockage of a major vessel by soft atheroma is catastrophic.

Further we also found that the 8 ventricular ruptures in the series were associated with this pattern of myocardial damage.

Double episode lesions In group D are 37 hearts where the acute myocardial lesions have two components, a massive recent component superimposed on a smaller and earlier component. The earlier part could usually be seen readily with the eye, and might have been considered the only lesion present but for the use of Nitro-BT which directed attention to the more recent part. Microscopically there was a distinct and unequivocal age difference of at least 24 hours between the two different parts of the lesions. In group D the arterial occlusions are characterized by very recent thrombi formed on ulcerated soft atheromatous plaques; thus the composition of the myocardial lesions suggests that the earlier components may be due to ulceration of the soft plaques (possibly with embolism within the coronary system), while the terminal and fatal components were related with the added thrombus. The features of the terminal lesions and of the thrombi do not allow us to decide which was primary, though it is significant that no thrombi were seen in the other coronary arteries.

Progressive lesions In 27 hearts the recent myocardial damage was obviously a progressive lesion occurring over several days with myocardial changes ranging from recent ischaemia to early organization. Fifteen of the hearts were associated with ulcerated soft atheromatous plaques, and it is possible that recurrent embolization of pultaceous atheromatous debris into the smaller coronary arterial branches may cause these lesions. Terminal myocardial damage and death could occur following occlusion of the major branches of the coronary artery either by massive atheromatous embolization or recent thrombus.

In a further 9 hearts occlusive thrombi alone occurred in the coronary arteries. The majority of these thrombi showed different age components, but we are not able to decide their relation to the myocardial lesions.

We wish to thank our colleagues in this department and in the Coronary Care Unit of the Royal Infirmary of Edinburgh for their co-operation; Mr James Paul of the Department of Medical Photography for the photographs; and our technicians, Mrs. Sheila Wilson and Miss Denise Bell, for their skill in preparing the histological sections, especially the large number of serial sections.

\section{References}

Branwood, A. W., and Montgomery, G. L. (1956). Observations on the morbid anatomy of coronary artery disease. Scottish Medical fournal, 1, 367.

Constantinides, P. (1965). Experimental Atherosclerosis. Elsevier Publishing Company, Amsterdam. (1966). Plaque fissures in human coronary thrombosis. Fournal of Atherosclerosis Research, 6, I.

Crawford, T., Dexter, D., and Teare, R. D. (I96I). Coronary-artery pathology in sudden death from myocardial ischaemia. A comparison by age-groups. Lancet, I, 181. 
Davenport, A. B. (1928). Spontaneous heart rupturea statistical summary. American fournal of the Medical Sciences, 176, 62.

Friedman, M., and Van den Bovenkamp, G. J. (1966). The pathogenesis of a coronary thrombus. American fournal of Pathology, 48, 19.

Gore, I. (1963). Ulceration of and embolization by atheromata. In Evolution of the Atherosclerotic Plaque, p. 315. Ed. by R. J. Jones. The University of Chicago Press.

Gross, H., and Sternberg, W. H. (1939). Myocardial infarction without significant lesions of coronary arteries. Archives of Internal Medicine, 64, 249.

Kagan, A., Livsic, A. M., Sternby, N., and Vihert, A. M. (1968). Coronary-artery thrombosis and the acute attack of coronary heart-disease. Lancet, 2 , II99.

Lawrie, D. M., Greenwood, T. W., Goddard, M., Harvey, A. C., Donald, K. W., Julian, D. G., and Oliver, M. F. (1967). A coronary-care unit in the routine management of acute myocardial infarction. Lancet, 2, 109.

Leary, T. (1935). Pathology of coronary sclerosis. American Heart fournal, ro, 328.

Lodge-Patch, I. (I95I). The ageing of cardiac infarcts, and its influence on cardiac rupture. British Heart fournal, 13, 37.

Mallory, G. K., White, P. D., and Salcedo-Salgar, J. (1939). The speed of healing of myocardial infarction. American Heart fournal, 18, 647.

Master, A. M., Gubner, R., Dack, S., and Jaffe, H. L. (194I). Differentiation of acute coronary insufficiency with myocardial infarction from coronary occlusion. Archives of Internal Medicine, 67, 647.

, Jaffe, H. L., Dack, S., and Grishman, A. (1944). Coronary occlusion, coronary insufficiency, and angina pectoris. American Heart fournal, 27, 803.

Montgomery, G. L. (1959). Problems in the pathology of coronary artery disease. In Lectures on the Scientific Basis of Medicine, vol. VII, 1957-58, p. 162. British Postgraduate Medical Federation, University of London.

Nachlas, M. M., and Shnitka, T. K. (1963). Macroscopic identification of early myocardial infarcts by alterations in dehydrogenase activity. American fournal of Pathology, 42, 379.

Paterson, J. C. (1936). Vascularization and hemorrhage of the intima of arteriosclerotic coronary arteries. Archives of Pathology, 22, 313. 